OPEN ACCESS

Edited by:

Chih-Wen Lin

E-Da Hospital, Taiwan

Reviewed by:

Adriano Pellicelli,

San Camillo-Forlanini Hospital, Italy

Sairah Ahmed,

University of Texas MD Anderson Cancer Center, United States

*Correspondence:

Wei-Lun Tsai

wltsai@vghks.gov.tw

Specialty section: This article was submitted to

Gastroenterology,

a section of the journa

Frontiers in Medicine

Received: 22 January 2021 Accepted: 24 June 2021

Published: 15 July 2021

Citation:

Sun $W-C$, Tang $P$-L, Chen W-C

Tsay F-W, Wang H-M, Tsai T-J, Kao S-S, Cheng J-S and Tsai W-L (2021) Hepatitis B Virus Screening Before Cancer Chemotherapy in

Taiwan: A Nationwide

Population-Based Study

Front. Med. 8:657109.

doi: 10.3389/fmed.2021.657109

\section{Hepatitis B Virus Screening Before Cancer Chemotherapy in Taiwan: A Nationwide Population-Based Study}

\author{
Wei-Chih Sun ${ }^{1,2}$, Pei-Ling Tang ${ }^{3,4,5}$, Wen-Chi Chen ${ }^{1,2}$, Feng-Woei Tsay ${ }^{1,2}$, \\ Huay-Min Wang ${ }^{1,2}$, Tzung-Jiun Tsai ${ }^{1,2}$, Sung-Shuo Kao ${ }^{1,2}$, Jin-Shiung Cheng ${ }^{1,2}$ and \\ Wei-Lun Tsai ${ }^{1,2,6 *}$ \\ ${ }^{1}$ Division of Gastroenterology and Hepatology, Department of Internal Medicine, Kaohsiung Veterans General Hospital, \\ Kaohsiung, Taiwan, ${ }^{2}$ School of Medicine, National Yang-Ming University, Taipei, Taiwan, ${ }^{3}$ Research Center of Medical \\ Informatics, Kaohsiung Veterans General Hospital, Kaohsiung, Taiwan, ${ }^{4}$ College of Nursing, Kaohsiung Medical University, \\ Kaohsiung, Taiwan, ${ }^{5}$ Department of Nursing, Meiho University, Pingtung, Taiwan, ${ }^{6}$ Department of Medical Education and \\ Research, Kaohsiung Veterans General Hospital, Kaohsiung, Taiwan
}

Background: Reactivation of the hepatitis B virus (HBV) during cancer chemotherapy is a severe and sometimes fatal complication. In 2009, the National Health Insurance (NHI) in Taiwan recommended and reimbursed screening for HBV infection and prophylactic antiviral therapy before cancer chemotherapy. In this study, we determined the HBV screening rate in patients with cancer undergoing chemotherapy in Taiwan.

Methods: We retrospectively collected data from the National Health Insurance Research Database on patients who received systemic chemotherapy for solid or hematologic cancers from January 2000 through December 2012. We defined HBV screening based on testing for serum HBsAg within 2 years of the first chemotherapy commencement. We calculated overall and annual HBV screening rates in all patients and subgroups of age, gender, cancer type, hospital level, physician's department, and implementation of $\mathrm{NHI}$ reimbursement for HBV screening before cancer chemotherapy.

Results: We enrolled 379,639 patients. The overall HBV screening rate was $45.9 \%$. The screening rates were higher in males, those with hematological cancer, those at non-medical centers and medical departments. The HBV screening rates before (2000-2008) and after the implementation of $\mathrm{NHI}$ reimbursement (2009-2012) were 38.1 and $57.5 \%$, respectively $(p<0.0001)$. The most common practice pattern of HBV screening was only HBsAg (64.6\%) followed by HBsAg/HBsAb (22.1\%), and $\mathrm{HBsAg} / \mathrm{HBcAb} / \mathrm{HBsAb}(0.7 \%)(p<0.0001)$. The annual HBV screening rate increased from 31.5 to $66.3 \%(p<0.0001)$. The screening rates of solid and hematological cancers significantly increased by year; however, the trend was greater in solid cancer than in hematological cancer (35.9 and 26.2\%, $p<0.0001$ ).

Conclusions: The HBV screening rate before cancer chemotherapy was fair but increased over time. These figures improved after implementing a government-based strategy; however, a mandatory hospital-based strategy might improve awareness of HBV screening and starting prophylactic antiviral therapy before cancer chemotherapy.

Keywords: hepatitis, hepatitis B virus, HBV screening, cancer, chemotherapy 


\section{INTRODUCTION}

Hepatitis B virus (HBV) is a global health problem. There are approximately two billion people worldwide affected by HBV. According to the 2017 global hepatitis report of the World Health Organization, an estimated 257 million people have chronic HBV infection, which can lead to significant morbidity from cirrhosis and hepatocellular carcinoma (1). Patients with HBV infection are at risk of reactivation when receiving immunosuppressive therapies for various diseases that disturb the host immune system and lead to the reactivation of $\mathrm{HBV}$ replication (2). In patients with cancer undergoing chemotherapy, HBV reactivation's incidences were $14-89 \%$ for hematological cancer and $4-68 \%$ for solid cancer, depending on the chemotherapy regimen and HBV serologic status (3-6). HBV reactivation can result in severe hepatitis, hepatic failure, or death $(2,3,7)$. Cancer outcomes may be compromised if cancer treatment is delayed or interrupted by reactivated hepatitis (8). Fortunately, prophylaxis with antiviral agents before chemotherapy reduces HBV reactivation and prevents fatal events (9-11). However, clinicians cannot initiate prophylaxis until the identification of HBV infection. Although there are debates about the best screening pattern, most agencies agree on the importance of HBV screening before chemotherapy. These agencies include the US Centers for Disease Control and Prevention (12), American Association for the Study of Liver Disease (13), European Association for the Study of the Liver (14), and Asian Pacific Association for the Study of the Liver (15). Only the American Society of Clinical Oncology suggests HBV screening for patients who receive specific highly cytotoxic or immunosuppressive therapies such as stem cell transplants or treatment with rituximab (16). Surprisingly, the HBV screening rates before chemotherapy were very low in non-HBV-endemic countries.

The reported screening rates were $16 \%$ at the Mayo Clinic (17), 17\% at the MD Anderson Cancer Center in the US (18), and $14-31 \%$ in Canada (19). Even in HBVendemic countries such as China, only $17 \%$ of patients at the West China Hospital receive HBV screening before chemotherapy (20). In Taiwan, a high endemic region of HBV infection (21), we followed HBV management guidelines published in 2003 (22) and updated in 2008 (23) by the working party of the Asian Pacific Association for the Study of the Liver. The 2003 guidelines recommend that patients who are HBsAg positive undertaking cancer chemotherapy need close monitoring for reactivation and promptly start antiviral therapy before decompensation develops (22). The 2008 guidelines further recommend HBsAg screening before cancer chemotherapy, with the administration of prophylactic antiviral therapy if HBsAg-positive; since 2009, the National Health Insurance (NHI) reimbursed the costs (23). Nevertheless, it has not yet been clarified whether proper HBV screening before cancer chemotherapy is performed in accordance with the NHI guideline. Therefore, we determined the status of HBV screening in patients undergoing cancer chemotherapy in Taiwan.

\section{METHODS}

\section{Data Source}

We conducted this retrospective study using the Taiwan National Health Insurance Research Database (NHIRD). Since 1995 in Taiwan, the NHI Program financed the healthcare of more than $99 \%$ of residents. The NHIRD includes detailed information from patients' medical records admitted to hospitals; these data include age, sex, diagnosis, interventions, medications, and survival data. This study was approved by the Ethics Committee and the institutional Review Board of the Kaohsiung Veterans General Hospital (VGHKS15-EM10-02). This was a retrospective study using NHIRD that comprises de-identified data, so informed consent was waived. Our hospital's Human Research Committee approved our use of the NHIRD data.

\section{Definition of Cancer Population and HBV Screening}

From January 1, 2000, through December 31, 2012, prospective participants were the 386,390 newly diagnosed patients with cancer (ICD-9-CM 140-195, 200-208) who received their first systemic chemotherapy, including intraarterial, intravenous, or oral chemotherapy. We excluded patients with undetermined sex or younger than 18 years old, leaving 379,639 unique patients. We identified HBV screening based on testing for hepatitis B surface antigen (HBsAg) for any reason within 2 years before chemotherapy initiation. We recorded testing for hepatitis B core antibody (anti-HBc) and hepatitis B surface antibody (anti-HBs) to investigate the practice patterns of HBV screening.

\section{Outcome Measures and Statistical Analyses}

We calculated HBV screening rates in the entire population of 379,639 patients. In subgroup analyses, we compared HBV screening rates using the chi-squared test for the following categories: age, gender; cancer type (solid cancer vs. hematological cancer); hospital level (medical center vs. non-medical center); and physician's department (medical department vs. surgical department). In Taiwan, the medical center has to qualify legal requirement in medical institutional setting, can provide 25 divisions of medical services with more than 25 psychiatric acute beds, and should acquire two qualifications including "Emergency responsible hospital in severely level" and "Cancer-care Quality Certification Program." We evaluated practice patterns of HBV screening using analysis of variance for subgroup analyses. For patients receiving chemotherapy before (2000-2008) vs. after (20092012) implementing Taiwan NHI reimbursement since 2009, we compared overall and subgrouping HBV screening rates using the chi-squared test. We used the Cochran-Armitage test to calculate trends in HBV screening rates by years. To identify factors associated with $\mathrm{HBV}$ screening, we used a logistic regression analysis. The predictive factors included age, sex, cancer types, physician's departments, and Taiwan NHI reimbursement implementation. We used the SPSS software (version 10.1; Chicago, IL, USA) for all statistical calculations. A two-sided $p<0.05$ was statistically significant. 
TABLE 1 | Demographic data of all patients (Total $N=379,639$ ).

\begin{tabular}{lc}
\hline & Number of patients (\%) \\
\hline Age (mean \pm S.D.) & $58.4 \pm 13.5$ \\
$<35$ years & $15,900(4.2 \%)$ \\
$35-69$ years & $278,812(73.4 \%)$ \\
Z70 years & $84,927(22.4 \%)$ \\
Gender & \\
Female & $176,257(46.4 \%)$ \\
Male & $203,382(53.6 \%)$ \\
Cancer type & \\
Hematological cancer & $23,898(6.3 \%)$ \\
Solid cancer & $355,741(93.7 \%)$ \\
Hospital level & \\
Medical center & $251,192(66.2 \%)$ \\
$\begin{array}{l}\text { Non-medical center } \\
\text { Physician's department }\end{array}$ & $128,447(33.8 \%)$ \\
Medical department & \\
$\begin{array}{l}\text { Surgical department } \\
\text { Other }\end{array}$ & \\
Era before and after the & \\
implementation of NHI reimbursement & \\
for HBV screening and prophylactic & $231,678(61.0 \%)$ \\
chemotherapy & $145,748(38.4 \%)$ \\
After: $2009-2012$ & $2,213(0.6 \%)$ \\
\hline & \\
\hline & \\
\hline & \\
\hline
\end{tabular}

\section{RESULTS}

Table 1 displays the demographic data of all 379,639 patients, including 203,382 (53.6\%) males and 176,257 (46.4\%) females. The mean age of all patients was 58.4 years. Solid cancers and hematological cancers accounted for 355,741 (93.7\%) and 23,898 (6.3\%) patients, respectively. There were 251,192 (66.2\%) patients from medical centers and 128,447 (33.8\%) patients from non-medical centers. The number and proportion of patients treated at medical, surgical, and other departments were 231,678 (61.0\%), $145,748(38.4 \%)$, and $2,213(0.6 \%)$, respectively. A total of $227,914(60.0 \%)$ and $151,725(40.0 \%)$ patients initiated cancer chemotherapy before (2000-2008) and after (2009-2012) the implementation of Taiwan NHI reimbursement for HBV screening and prophylactic antiviral therapy in patients with cancer undergoing chemotherapy.

Table 2 displays the HBV screening rates in all patients and subgroup analyses. The overall screening rate was $45.9 \%$ $(174,141 / 379,639)$. The HBV screening rates were significantly higher in males than in females ( 48.6 vs. $42.7 \%, p<0.0001$ ), in hematological than solid cancers (79.1 and 43.6\%, $p<0.0001$ ), in patients from non-medical than from medical centers (49.2 and $44.2 \%, p<0.0001$ ), in patients treated in medical than in surgical departments (55.4 and $30.9 \%, p<0.0001$ ), and in the era after (2009-2012) than before (2000-2008) the Taiwan NHI reimbursement for $\mathrm{HBV}$ screening and prophylactic antiviral therapy in patients with cancer undergoing chemotherapy (57.5 and $38.1 \%$, respectively, $p<0.0001$ ).

Table 3 displays the practice patterns of HBV screening before cancer chemotherapy. For all patients, $64.6 \%(n=112,428)$ received testing for only $\mathrm{HBsAg}$ before cancer chemotherapy, $22.1 \%(n=38,404)$ for HBsAg/HBcAb-IgG, and $0.7 \%(n=$ $8,187)$ for $\mathrm{HBsAg} / \mathrm{HBcAb}-\mathrm{IgG} / \mathrm{HBsAb}(p<0.0001)$. In subgroup analyses, the most common HBV screening pattern before cancer chemotherapy was testing for only HBsAg followed by $\mathrm{HBs} \mathrm{Ag} / \mathrm{HBcAb}-\mathrm{IgG}$ and $\mathrm{HBs} \mathrm{Ag} / \mathrm{HBcAb}-\mathrm{IgG} / \mathrm{HBsAb}$.

Figure 1 displays the evolution of annual $\mathrm{HBV}$ screening rates in all patients. These rates increased from $31.5 \%$ in 2000 to $66.3 \%$ in $2012(p<0.0001)$. Figure 2 shows the evolution of annual HBV screening rates in patients with hematological and solid cancers. These rates increased from 64.5 to $90.7 \%(p<0.0001)$ in hematological cancers and from 28.7 to $64.6 \%(p<0.0001)$ in solid cancers, respectively. Patients with solid cancers had a greater increase in $\mathrm{HBV}$ screening $(35.9 \%)$ than patients with hematological cancers $(26.2 \%)(p<0.0001)$.

We further investigated the increase in HBV screening rates using a logistic regression analysis. Table 4 displays the multivariate analysis. Factors associated with screening included age $(\mathrm{OR}=0.99, p<0.0001)$, male sex $(\mathrm{OR}=1.17, p<0.0001)$, medical department $(\mathrm{OR}=2.64, p<0.0001)$, hematological cancer (OR $=3.63, p<0.0001)$, and era (2009-2012) after NHI reimbursement for HBV screening before cancer chemotherapy $(\mathrm{OR}=2.46, p<0.0001)$.

\section{DISCUSSION}

Cancer chemotherapy-induced HBV reactivation is a severe complication because it can cause fatal liver injury (24). Prophylactic anti-HBV therapy before chemotherapy for both hematological and solid cancers can prevent this complication. Effective prophylaxis is available; however, it depends on adequate detection of prior HBV infection. A study showed that early HBV identification correlated with the early use of anti-HBV therapy and reduced the risk of fatal liver failure in patients with HBV receiving cancer chemotherapy (25). If HBV screening does not occur before cancer chemotherapy, strategies to prevent HBV reactivation are meaningless. Recommendations for routine HBV screening before cancer chemotherapy appear in many guidelines; nevertheless, adherence is generally low. In this large cohort study, we measured HBV screening rates before cancer chemotherapy in Taiwan. We found that the overall HBV screening rate was suboptimal (45.9\%) but higher than those reported in many other countries (14-34\%) (17-22, 26, 27).

The subgroup analyses showed that the overall HBV screening rate was lower in older patients, female patients, those with solid cancers, and those treated in medical centers and surgical departments. The prevalence of HBV increases with age (28); therefore, older patients are more likely to undergo $\mathrm{HBV}$ infection testing. Our finding of lower HBV screening rates among older patients might be an underestimate, because we defined HBV screening as testing for serum HBsAg within 2 years of the commencement of first chemotherapy; this constraint may 
TABLE 2 | HBV screening rates in whole patients and subgroup analyses.

\begin{tabular}{|c|c|c|c|}
\hline & Number of patients & $\%$ & $p$-value \\
\hline Overall & 174,141 & $45.9 \%(174,141 / 379,639)$ & \\
\hline Age & & & $<0.0001$ \\
\hline$<35$ years & 8,572 & $53.9 \%(8,572 / 15,900)$ & \\
\hline 35-69 years & 131,454 & $47.1 \%(131,454 / 278,812)$ & \\
\hline$\geqq 70$ years & 34,115 & $40.2 \%(34,115 / 84,927)$ & \\
\hline Gender & & & $<0.0001$ \\
\hline Female & 75,234 & $42.7 \%(75,234 / 176,257)$ & \\
\hline Male & 98,907 & 48.6\% (98,907/203,382) & \\
\hline Cancer type & & & $<0.0001$ \\
\hline Hematological cancer & 18,913 & $79.1 \%(18,913 / 23,898)$ & \\
\hline Solid cancer & 155,228 & $43.6 \%(155,228 / 355,741)$ & \\
\hline Hospital level & & & $<0.0001$ \\
\hline Medical center & 110,955 & $44.2 \%(110,955 / 251,192)$ & \\
\hline Non-medical center & 63,186 & $49.2 \%(63,186 / 128,447)$ & \\
\hline Physician's department & & & $<0.0001$ \\
\hline Medical department & 128,153 & $55.3 \%(128,153 / 231,678)$ & \\
\hline Surgical department & 45,150 & $30.9 \%(45,150 / 145,748)$ & \\
\hline $\begin{array}{l}\text { Era before and after the implementation of NHI } \\
\text { reimbursement for HBV screening and } \\
\text { prophylactic antiviral therapy before cancer } \\
\text { chemotherapy }\end{array}$ & & & $<0.0001$ \\
\hline Before: 2000-2008 & 86,902 & $38.1 \%(86,902 / 227,914)$ & \\
\hline After: 2009-2012 & 87,239 & $57.5 \%(87,239 / 151,725)$ & \\
\hline
\end{tabular}

TABLE 3 | Practice patterns of HBV screening in whole patients and subgroup analyses.

\begin{tabular}{|c|c|c|c|c|}
\hline & HBsAg & HBsAg HBcAb-IgG & HBsAg HBcAb-IgG HBsAb & $p$-value \\
\hline Overall & $127,550(73.2 \%)$ & $38,404(22.1 \%)$ & 8,187 (4.7\%) & $<0.0001$ \\
\hline \multicolumn{5}{|l|}{ Age } \\
\hline$<35$ years & $6,092(71.1 \%)$ & $2,053(24.0 \%)$ & 427 (4.9\%\%) & $<0.0001$ \\
\hline 35-69 years & 96,155 (73.1\%) & 28,952 (22.1\%) & $6,347(4.8 \%)$ & $<0.0001$ \\
\hline$\geqq 70$ years & 25,303 (74.2\%) & $7,399(21.7 \%)$ & $1,413(4.1 \%)$ & $<0.0001$ \\
\hline \multicolumn{5}{|l|}{ Gender } \\
\hline Female & $55,686(74.0 \%)$ & 15,147 (20.2\%) & $4,401(5.8 \%)$ & $<0.0001$ \\
\hline Male & $71,864(72.7 \%)$ & 23,257 (23.5\%) & $3,786(3.8 \%)$ & $<0.0001$ \\
\hline \multicolumn{5}{|l|}{ Cancer type } \\
\hline Hematological cancer & 13,023 (68.9\%) & $4,809(25.4 \%)$ & $1,081(5.7 \%)$ & $<0.0001$ \\
\hline Solid cancer & $114,527(73.8 \%)$ & 33,595 (21.6\%) & $7,106(4.6 \%)$ & $<0.0001$ \\
\hline \multicolumn{5}{|l|}{ Hospital level } \\
\hline Medical center & $76,951(69.4 \%)$ & $27,823(25.1 \%)$ & $6,181(5.5 \%)$ & $<0.0001$ \\
\hline Non-medical center & $50,599(80.1 \%)$ & $10,581(16.7 \%)$ & $2,006(3.2 \%)$ & $<0.0001$ \\
\hline \multicolumn{5}{|c|}{ Physician's department } \\
\hline Medical department & 96,498 (75.3\%) & 25,893 (20.2\%) & $5,762(4.5 \%)$ & $<0.0001$ \\
\hline Surgical department & 30,388 (67.3\%) & 12,338 (27.3\%) & $2,413(5.4 \%)$ & $<0.0001$ \\
\hline
\end{tabular}

miss patients who underwent testing more than 2 years prior. In Taiwan, males have higher HBsAg carrier rates than females and males are more likely to be tested for HBV infection (29); this finding is similar to our present result. Physicians in medical departments and physicians who have treated hematological cancer tend to know the risk of HBV flares and may be more aware of guidelines regarding $\mathrm{HBV}$ screening and prophylactic antiviral therapy before cancer chemotherapy (30). Therefore, our finding of lower HBV screening rates in surgical departments and solid cancer was reasonable. As for lower screening rates in medical centers, physicians in higher-level hospitals might theoretically pay more attention to cancer chemotherapy-related 


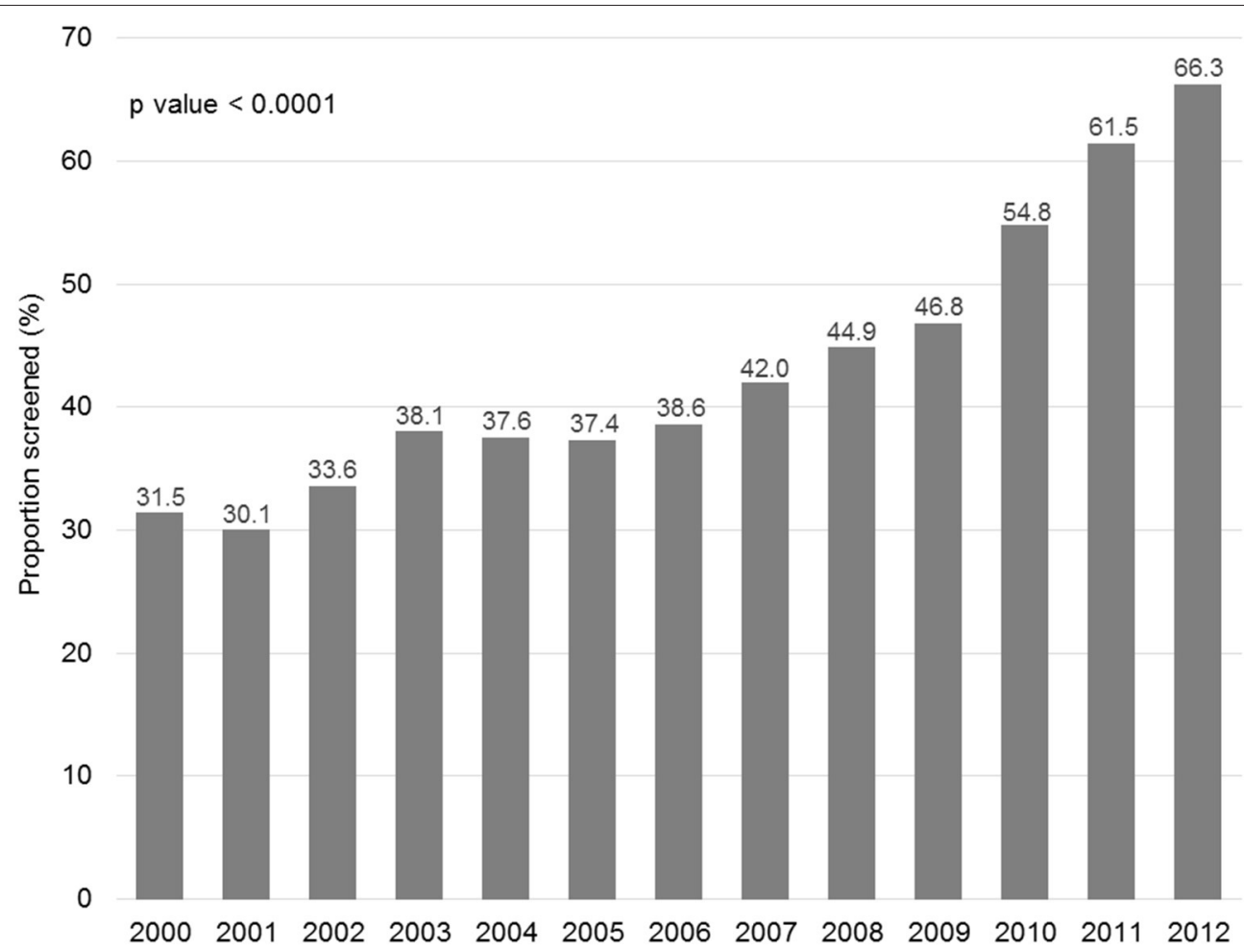

FIGURE 1 | Changes in the annual HBV screening rate.

$\mathrm{HBV}$ reactivation; therefore, the HBV screening rate should be higher. Kwak reported that HBV screening was less common in community clinics than in teaching hospitals (31). However, our previous study demonstrated low physicians' compliance with $\mathrm{HBV}$ screening before cancer chemotherapy in a single medical center (32). A lower hospital level does not necessarily correlate with less knowledge, awareness, or adherence to screening guidelines.

Conversely, physicians who treat larger numbers of patients in medical centers may underestimate the risk of HBV reactivation during cancer chemotherapy and may neglect HBV screening. As for the HBV screening patterns, most patients received testing only for HBsAg, and few underwent universal testing for $\mathrm{HBs} \mathrm{Ag} / \mathrm{HBcAb}-\mathrm{IgG} / \mathrm{HBsAb}$ regardless of the age, gender, cancer type, hospital level, or physician department. This is reasonable because our guidelines recommend only $\mathrm{HBsAg}$ testing. The recommendation of our guidelines is different from the ASCO guidelines which suggest testing for HBV by all 3 tests of $\mathrm{HBs} A g / \mathrm{HBcAb}-\mathrm{IgG} / \mathrm{HBs} \mathrm{Ab}$ in patients undergoing highly cytotoxic or immunosuppressive therapies. From the perspective of cost-effectiveness, a recent study found that universal HBV screening before chemotherapy for solid cancer was not cost effective, whereas screening for HBsAg alone was a cost-effective approach (33). However, we did not collect the data to compare the difference in cost-effectiveness of pre-chemotherapy HBV screening between solid and hematological cancers.

Although the overall HBV screening rate was unsatisfactory, it is encouraging that the annual HBV screening rate increased from $31.5 \%$ in 2000 to $66.3 \%$ in 2012 . Both hematological and solid cancers increased annual HBV screening rates; however, the ascending trend was more significant for solid cancers. Our result was different from the results of a survey from the Mayo Clinic (17) and a nationwide survey in Japan (34) that found that HBV screening rates in solid cancer were relatively low and did not increase over time. Potential explanations for a more significant improvement of HBV screening in solid cancers in our study may include (I) that patients with solid cancers had lower baseline annual HBV screening rates so there was larger scope for improvement, and (II) that our strategies to improve HBV screening were more intensive and had a higher impact on patients with solid cancers.

To improve HBV screening before cancer chemotherapy, it is essential to improve awareness among physicians regarding the risk of $\mathrm{HBV}$ reactivation during cancer chemotherapy. In a study from St. Michael Hospital in Canada, the screening rate only increased from 14 to $31 \%$ after an education intervention (19). In a recent nationwide population-based study from Japan, the screening rate only increased from 51.3 to $67.1 \%$ after the Japanese guidelines' announcement (34). In Taiwan, the strategy to improve HBV screening was NHI reimbursement for HBV screening and prophylactic antiviral therapy in patients with cancer receiving chemotherapy, which began in 2009. Our government-based strategy successfully raised the average HBV screening rate from $38.1 \%$ in $2000-2008$ to $57.5 \%$ in 2009-2012. Although the government-based strategy was supposed to be mandatory and legally binding, the annual 


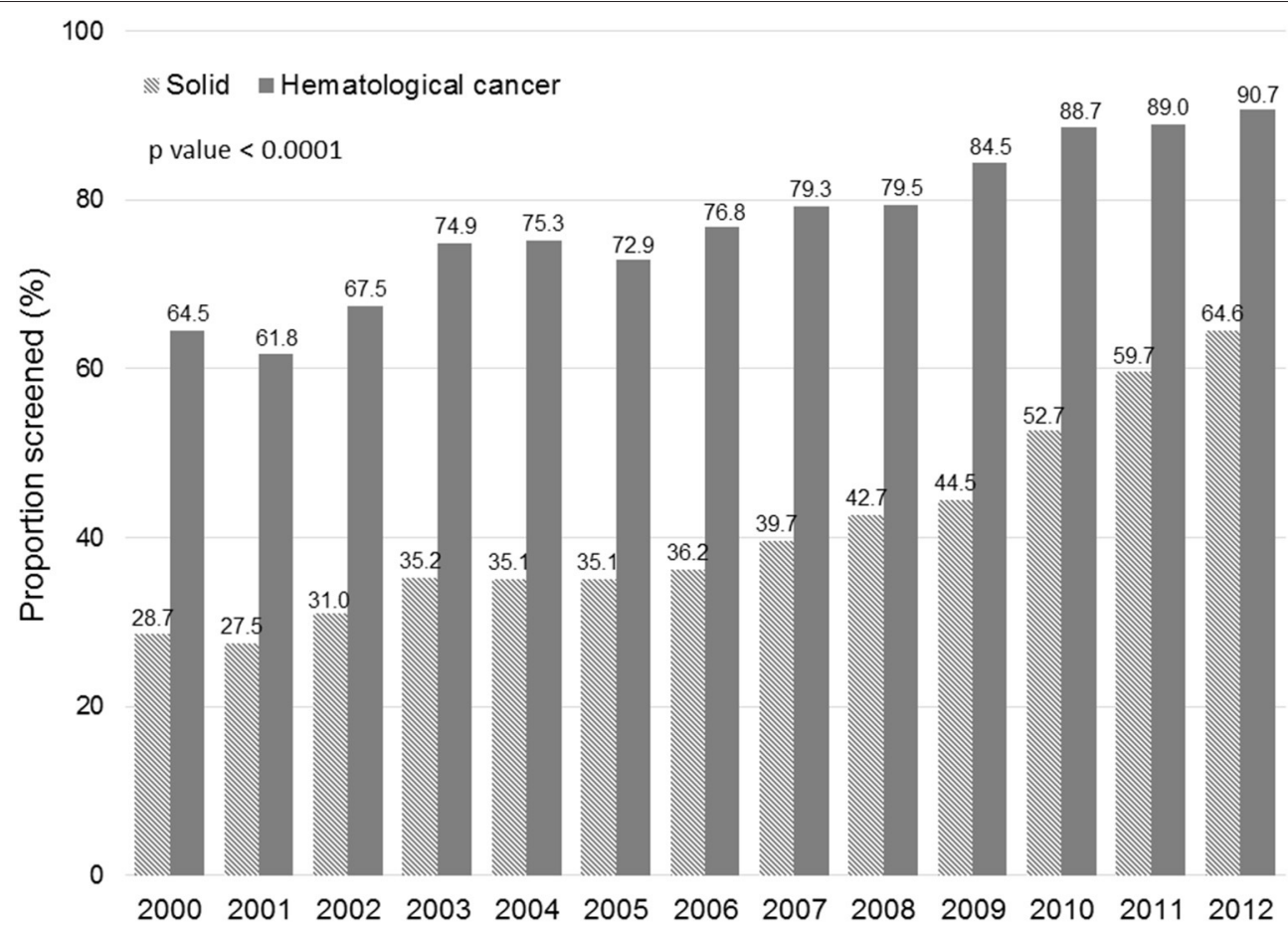

FIGURE 2 | Changes in the annual HBV screening rate in solid and hematological cancers.

TABLE 4 | Factors related to HBV screening before cancer chemotherapy.

\begin{tabular}{lccc}
\hline & \multicolumn{2}{c}{ Screening for HBV (HBsAg) } \\
\cline { 2 - 4 } Clinical factor & Odds ratio & $\mathbf{9 5 \%}$ Cl & \multicolumn{1}{c}{-value } \\
\hline Age & 0.985 & $0.985-0.986$ & $<0.0001$ \\
Male vs. female & 1.166 & $1.150-1.182$ & $<0.0001$ \\
Hematological cancer vs. solid cancer & 3.627 & $3.509-3.749$ & $<0.0001$ \\
Medical department vs. surgical department & 2.641 & $2.602-2.680$ & $<0.0001$ \\
Era 2 vs. Era 1 & 2.456 & $2.422-2.491$ & $<0.0001$ \\
\hline
\end{tabular}

${ }^{\star}$ Era before (Ear 1: 2000-2008) and after (Era 2: 2009-2012) the implementation of NHI reimbursement for HBV screening and prophylactic antiviral therapy before cancer chemotherapy.

HBV screening rate only achieved $66.3 \%$ in 2012 . Some doctors failed to perform HBV screening before cancer chemotherapy due to underestimation of risk of $\mathrm{HBV}$ reactivation during cancer chemotherapy, low knowledge regarding the risk for $\mathrm{HBV}$ infection, and unawareness of guidelines regarding HBV screening in cancer chemotherapy. Poor compliance with government-based strategy was the main obstacle, and this finding was similar to the results of our previous study. Our hospital developed a novel computer-assisted system that made HBV screening before cancer chemotherapy routine in daily clinical practice to improve poor compliance. In our hospital, the annual screening rate increased from $25.6 \%$ in 2009 to $92.3 \%$ in 2012. This finding suggests that a hospital-based strategy is also necessary to improve HBV screening in cancer chemotherapy. Just as the findings of a study from the Peter MacCallum Cancer Center in Australia, most physicians (71\%) reported that hospital-based policy was the main driver of their practice (35).

Our study's strengths include a large cohort of patients and the provision of strategies to improve the HBV screening rate before cancer chemotherapy in an HBV-endemic area. There were some limitation in our study: (I) the definition of HBV screening before cancer chemotherapy used in our study may overestimate the screening rate; (II) although the screening rate improved based on government-based strategies, we did not know the evolution of prophylactic rate and HBV associated complications; nevertheless, whether improved screening correlates with the commencement of prophylaxis or reduced chemotherapy-induced HBV reactivation is unclear because the NHIRD does not provide more detailed laboratory results to define the outcomes; (III) we did not collect the data of detailed individual chemotherapy agents to show the difference 
of HBV screening based risk stratification for HBV reactivation; (IV) a nationwide vaccination program since 1983 decreased the prevalence of HBV infection in Taiwan, suggesting the need for further evaluation of the cost-effectiveness of current strategies for HBV screening before cancer chemotherapy.

\section{CONCLUSIONS}

Before cancer chemotherapy, the HBV screening rate remained unsatisfactory but gradually increased following the implementation of a government-based strategy. A hospitalbased strategy may improve awareness of HBV reactivation during cancer chemotherapy. Policies are necessary to improve HBV screening before cancer chemotherapy.

\section{DATA AVAILABILITY STATEMENT}

The data analyzed in this study is subject to the following licenses/restrictions: Data are available from the National Health Insurance Research Database (NHIRD), which is managed by the National Health Research Institute (NHRI). The raw data cannot

\section{REFERENCES}

1. World Health Organization. Hepatitis B. Fact Sheet 204. Available online at: http://www.who.int/mediacentre/factsheets/fs204/en/ (accessed January 8, 2018).

2. Di Bisceglie AM, Lok AS, Martin P, Terrault N, Perrillo RP, Hoofnagle JH. Recent US Food and Drug Administration warnings on hepatitis B reactivation with immune-suppressing and anticancer drugs: just the tip of the iceberg? Hepatology. (2015) 61:703-11. doi: 10.1002/hep.27609

3. Loomba R, Liang TJ. Hepatitis B reactivation associated with immune suppressive and biological modifier therapies: current concepts, management strategies, and future directions. Gastroenterology. (2017) 152:1297-309. doi: 10.1053/j.gastro.2017.02.009

4. Liu Z, Jiang L, Liang G, Song E, Jiang W, Zheng Y, et al. Hepatitis B virus reactivation in breast cancer patients undergoing chemotherapy: a review and meta-analysis of prophylaxis management. J Viral Hepat. (2017) 24:56172. doi: $10.1111 /$ jvh. 12672

5. Voican CS, Mir O, Loulergue P, Dhooge M, Brezault C, Dréanic J, et al. Hepatitis B virus reactivation in patients with solid tumors receiving systemic anticancer treatment. Ann Oncol. (2016) 27:217284. doi: 10.1093/annonc/mdw414

6. Yamada T, Nannya Y, Suetsugu A, Shimizu S, Sugihara J, Shimizu M, et al. Late reactivation of hepatitis $B$ virus after chemotherapies for hematological malignancies: a case report and review of the literature. Intern Med. (2017) 56:115-8. doi: 10.2169/internalmedicine.56.7468

7. Loomba R, Rowley A, Wesley R, Liang TJ, Hoofnagle JH, Pucino F, et al. Systematic review: the effect of preventive lamivudine on hepatitis B reactivation during chemotherapy. Ann Intern Med. (2008) 148:51928. doi: 10.7326/0003-4819-148-7-200804010-00008

8. Lok AS, Liang RH, Chiu EK, Wong KL, Chan TK, Todd D. Reactivation of hepatitis B virus replication in patients receiving cytotoxic therapy. Report of a prospective study. Gastroenterology. (1991) 100:182-8. doi: 10.1016/0016-5085(91)90599-G

9. Kohrt HE, Ouyang DL, Keeffe EB. Systematic review: lamivudine prophylaxis for chemotherapy-induced reactivation of chronic hepatitis B virus infection. Aliment Pharmacol Ther. (2006) 24:1003-16. doi: 10.1111/j.1365-2036.2006.03081.x

10. Martyak LA, Taqavi E, Saab S. Lamivudine prophylaxis is effective in reducing hepatitis $B$ reactivation and reactivation-related mortality be made publicly available. Formal applications should be sent to NHRI and reviewed for approval of data release. Requests to access these datasets should be directed to nhird@nhri.edu.tw.

\section{ETHICS STATEMENT}

This study was approved by the Ethics Committee and the institutional Review Board of the Kaohsiung Veterans General Hospital (VGHKS15-EM10-02). This was a retrospective study using NHIRD that comprises de-identified data, so informed consent was waived. Our hospital's Human Research Committee approved our use of the NHIRD data.

\section{AUTHOR CONTRIBUTIONS}

W-CS, W-CC, F-WT, H-MW, T-JT, S-SK, J-SC, and W-LT contributed to the study concept. W-CS and W-LT design the study. P-LT collected and analyzed the data. W-CS and P-LT performed the statistical analysis. W-CS wrote the draft. W-LT revised the manuscript and gave the final approval for the submission. All authors agreed to the submitted version.

in chemotherapy patients: a meta-analysis. Liver Int. (2008) 28:2838. doi: 10.1111/j.1478-3231.2007.01618.x

11. Katz LH, Fraser A, Gafter-Gvili A, Leibovici L, Tur-Kaspa R. Lamivudine prevents reactivation of hepatitis B and reduces mortality in immunosuppressed patients: systematic review and meta-analysis. J Viral Hepat. (2008) 15:89-102. doi: 10.1111/j.11365-2893.2007.00902.x

12. Weinbaum CM, Mast EE, Ward JW. Recommendation for identification and public health management of persons with chronic hepatitis B virus infection. Hepatology. (2009) 49:S35-44. doi: 10.1002/hep.22882

13. Terrault NA, Bzowej NH, Chang KM, Hwang JP, Jonas MM, Murad MH. AASLD guidelines for treatment of chronic hepatitis B. Hepatology. (2016) 63:261-83. doi: 10.1002/hep.28156

14. Lampertico P, Agarwal K, Berg T, Buti M, Janssen HLA, Papatheodoridis G, et al. EASL 2017 Clinical Practice Guidelines on the management of hepatitis B virus infection. J Hepatol. (2017) 67:370-98. doi: 10.1016/j.jhep.2017.03.021

15. Sarin SK, Kumar M, Lau GK, Abbas Z, Chan HL, Chen CJ, et al. Asian-Pacific clinical practice guidelines on the management of hepatitis B: a 2015 update Hepatol Int. (2016) 10:1-98. doi: 10.1007/s12072-015-9675-4

16. Hwang JP, Artz AS, Somerfield MR. Hepatitis B virus screening for Patients with cancer before therapy: American Society of Clinical Oncology provisional clinical opinion update. J Oncol Pract. (2015) 11:e4879. doi: 10.1200/JOP.2015.004846

17. Wi CI, Loo NM, Larson JJ, Moynihan TJ, Madde NR, Grendahl DC, et al. Low level of hepatitis B virus screening among patients receiving chemotherapy. Clin Gastroenterol Hepatol. (2015) 13:970-5. doi: 10.1016/j.cgh.2014.10.032

18. Hwang JP, Fisch MJ, Zhang H, Kallen MA, Routbort MJ, Lal LS, et al. Low rates of hepatitis B virus screening at the onset of chemotherapy. J Oncol Pract. (2012) 8:e32-9. doi: 10.1200/JOP.2011.000450

19. Lee R, Vu K, Bell CM, Hicks LK. Screening for hepatitis B surface antigen before chemotherapy: current practice and opportunities for improvement. Curr Oncol. (2010) 17:32-8. doi: 10.3747/co.v17i6.653

20. Wang Y, Luo XM, Yang D, Zhang J, Zhuo HY, Zhang J, et al. Testing for hepatitis B infection in prospective chemotherapy patients: a retrospective study. World J Gastroenterol. (2013) 19:923-30. doi: 10.3748/wjg.v19.i6.923

21. Liu CJ, Chen DS, Chen PJ. Epidemiology of HBV infection in Asian blood donors: emphasis on occult HBV infection and the role of NAT. J Clin Virol. (2006) 36:S33-44. doi: 10.1016/S1386-6532(06)80007-7

22. Liaw YF, Leung $\mathrm{N}$, Guan R, Lau GK, Merican I. AsianPacific consensus statement on the management of chronic 
hepatitis B: an update. J Gastroenterol Hepatol. (2003) 18:23945. doi: 10.1046/j.1440-1746.2003.03037.x

23. Liaw YF, Leung N, Kao JH, Piratvisuth T, Gane E, Han KH, et al. Asian-Pacific consensus statement on the management of chronic hepatitis B: a 2008 update. Hepatol Int. (2008) 2:263-83. doi: 10.1007/s12072-008-9080-3

24. Hsu PI, Lai KH, Cheng JS, Kao SS, Li YR, Sun WC, et al. Prevention of acute exacerbation of chronic hepatitis B infection in cancer patients receiving chemotherapy in a hepatitis B virus endemic area. Hepatology. (2015) 62:38796. doi: 10.1002/hep. 27843

25. Hwang JP, Suarez-Almazor ME, Cantor SB, Barbo A, Lin HY, Ahmed $\mathrm{S}$, et al. Impact of the timing of hepatitis $\mathrm{B}$ virus identification and anti-hepatitis B virus therapy initiation on the risk of adverse liver outcomes for patients receiving cancer therapy. Cancer. (2017) 123:336776. doi: 10.1002/cncr.30729

26. Khokhar OS, Farhadi A, McGrail L, Lewis JH. Oncologists and hepatitis B: a survey to determine current level of awareness and practice of antiviral prophylaxis to prevent reactivation. Chemotherapy. (2009) 55:6975. doi: 10.1159/000183731

27. Zurawska U, Hicks LK, Woo G, Bell CM, Krahn M, Chan KK, et al. Hepatitis $B$ virus screening before chemotherapy for lymphoma: a cost-effectiveness analysis. J Clin Oncol. (2012) 30:3167-73. doi: 10.1200/JCO.2011.40.7510

28. Lao TT, Sahota DS, Law LW, Cheng YK, Leung TY. Age-specific prevalence of hepatitis B virus infection in young pregnant women, Hong Kong Special Administrative Region of China. Bull World Health Organ. (2014) 92:7829. doi: 10.2471/BLT.13.133413

29. Su FH, Huang HY, Chang HJ, Jeng JJ, Liu YH, Chen CD. Forecasting the declining rate of chronic hepatitis-B carrier status at a Taiwanese university: twenty years after implementation of an universal $\mathrm{HBV}$ vaccination program in Taiwan. Chang Gung Med J. (2007) 30:521-8.

30. Lee RS, Bell CM, Singh JM, Hicks LK. Hepatitis B screening before chemotherapy: a survey of practitioners' knowledge, beliefs, and screening practices. J Oncol Pract. (2012) 8:325-8. doi: 10.1200/JOP.2012.000597
31. Kwak YE, Stein SM, Lim JK. Practice patterns in hepatitis B virus screening before cancer chemotherapy in a major US Hospital Network. Dig Dis Sci. (2018) 63:61-71. doi: 10.1007/s10620-017-4850-1

32. Sun WC, Hsu PI, Yu HC, Lin KH, Tsay FW, Wang HM, et al. The compliance of doctors with viral hepatitis $\mathrm{B}$ screening and antiviral prophylaxis in cancer patients receiving cytotoxic chemotherapy using a hospital-based screening reminder system. PLoS ONE. (2015) 10:e0116978. doi: 10.1371/journal.pone.0116978

33. Day FL, Karnon J, Rischin D. Cost-effectiveness of universal hepatitis B virus screening in patients beginning chemotherapy for solid tumors. J Clin Oncol. (2011) 29:3270-7. doi: 10.1200/JCO.2011.35.1635

34. Ikeda M, Yamamoto H, Kaneko M, Oshima H, Takahashi H, Umemoto $\mathrm{K}$, et al. Screening rate for hepatitis $\mathrm{B}$ virus infection in patients undergoing chemotherapy in Japan. Int J Clin Oncol. (2016) 21:11626. doi: 10.1007/s10147-016-0995-8

35. Day FL, Link E, Thursky K, Rischin D. Current hepatitis B screening practices and clinical experience of reactivation in patients undergoing chemotherapy for solid tumors: a nationwide survey of medical oncologists. J Oncol Pract. (2011) 7:141-7. doi: 10.1200/JOP.2010.00 0133

Conflict of Interest: The authors declare that the research was conducted in the absence of any commercial or financial relationships that could be construed as a potential conflict of interest.

Copyright (C) 2021 Sun, Tang, Chen, Tsay, Wang, Tsai, Kao, Cheng and Tsai. This is an open-access article distributed under the terms of the Creative Commons Attribution License (CC BY). The use, distribution or reproduction in other forums is permitted, provided the original author(s) and the copyright owner(s) are credited and that the original publication in this journal is cited, in accordance with accepted academic practice. No use, distribution or reproduction is permitted which does not comply with these terms. 